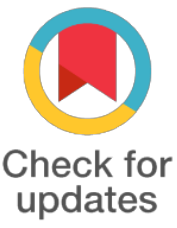

*For correspondence:

pvphuc@hcmus.edu.vn

Competing interests: The authors declare that no competing interests exist.

Received: 2017-06-27 Accepted: 2017-07-14 Published: 2017-09-05

Copyright The Author(s) 2017. This article is published with open access by BioMedPress (BMP).

This article is distributed under the terms of the Creative Commons Attribution License (CC-BY 4.0) which permits any use, distribution, and reproduction in any medium, provided the original author(s) and the source are credited

\section{Experimental reprogramming of murine embryonic fibroblasts towards induced pluripotent stem cells using a single polycistronic vector}

\author{
Oanh Thuy Huynh ${ }^{1}$, Mai Thi-Hoang Truong ${ }^{1}$, Phuc Van Pham ${ }^{1,2}$ \\ ${ }^{1}$ Laboratory of Stem Cell Research and Application, University of Science, Vietnam National \\ University, Ho Chi Minh City, Viet Nam \\ ${ }^{2}$ Laboratory of Cancer Research, University of Science, Vietnam National University, Ho Chi \\ Minh City, Viet Nam
}

\section{Abstract}

Background: Embryonic stem cells are pluripotent, thus capable of differentiating into all types of cells derived from the three germ layers. However, the application of embryonic stem cells (ESCs) for preclinical and clinical studies is difficult due to ethical concerns. Induced pluripotent stem cells (iPSCs) are derived from differentiation and have many ESC characteristics. The study herein examines the production of iPSCs from reprogramming of mouse embryonic fibroblasts (MEFs) via transduction with defined factors.

Methods: MEFs were collected from mouse embryos via a previously published protocol. The cells were transduced with a single polycistronic viral vector encoding mouse CDNAs of Oct3/4, Sox2, Klf4 and c-Myc. Transduced cells were treated and sub-cultured with ESC medium. The cells were evaluated as iPSCs with specific morphology, and expression SSEA-1, Oct3/4, Sox2 and Nanog. In addition, they were also evaluated for pluripotency by assessing alkaline phosphatase (AP) activity and in vivo teratoma formation.

Results: Under the reprogrammed conditions, the transduced cells displayed a change in morphology, forming ESC-like clusters. These cell clusters strongly expressed pluripotent markers as well as ESC-specific genes. Furthermore, the colonies exhibited higher AP activity and formed teratomas when injected into the murine testis.

Conclusion: The study herein suggests that MEFs can be reprogrammed into iPSCs using a polycistronic viral vector encoding mouse cDNAs for Oct3/4, Sox2, KIf 4 and c- Myc.

Keywords

Polycistronic vectors, Epigenetic reprogramming, iPSCs, Fibroblast reprogramming

Funding

References 